\title{
Electrochemical detection of L-serine and L-phenylalanine at bamboo charcoal-carbon nanosphere electrode
}

\author{
Mitali Saha $\cdot$ Soma Das
}

Received: 13 March 2014/ Accepted: 4 April 2014/Published online: 23 April 2014

(C) The Author(s) 2014. This article is published with open access at Springerlink.com

\begin{abstract}
A carbon nanosphere electrode $(\mathrm{CN})$ has been fabricated for the electrochemical detection of L-serine and L-phenylalanine. Electrochemical behavior of amino acids was investigated using cyclic voltammetry, differential pulse voltammetry, square wave voltammetry and linear sweep voltammetry. In optimal conditions, the peak current of both amino acids on the $\mathrm{CN}$ electrode was found to enhance greatly. A sensitive oxidation peak at $0.085 \mathrm{~V}$ was observed in the determination of L-serine and $0.06 \mathrm{~V}$ for L-phenylalanine. A linearity between the oxidation peak current and the concentration of both amino acids was obtained in the range of $1-100 \mu \mathrm{M}\left(R^{2}=0.99783\right.$ for L-serine, 0.99618 for L-phenylalanine). The practical application of the carbon nanosphere electrode in the determination of the amino acids possesses high selectivity, sensitivity and stability.
\end{abstract}

Keywords Carbon nanospheres $\cdot$ L-Serine ·

L-Phenylalanine

\section{Introduction}

L-Serine is an amino acid which contributes to several bodily processes, most notably in the functioning of RNA and DNA, formation of muscles, metabolism of fat/fatty acids, and the maintenance of a healthy immune system. $\mathrm{L}-$ Serine is also a component of cell membranes and is

M. Saha $\cdot$ S. Das $(\bowtie)$

Department of Chemistry, National Institute of Technology,

Agartala 799055, Tripura, India

e-mail: somachem17@gmail.com

M. Saha

e-mail: mitalichem71@gmail.com vital for the neurotransmission process that takes part between the brain and the various nerve endings in the body [1]. A deficiency in serine manifests itself through such symptoms as delayed cognitive and physical skills and seizures. Under development of the brain may also be traced to L-serine deficiency. In recent years, L-serine and the products of its metabolism have been recognized not only to be essential for cell proliferation, but also to be necessary for specific functions in the central nervous system [2].

L-Phenylalanine is an essential amino acid and used for the biochemical formation of proteins, coded for DNA. Phenylalanine is a precursor for tyrosine, the monoamine signaling molecules dopamine, norepinephrine (noradrenaline), and epinephrine (adrenaline), and the skin pigment melanin. L-Phenylalanine is an antagonist at $\alpha 2 \delta \mathrm{Ca}^{2+}$ calcium channels with a $\mathrm{Ki}$ of $980 \mathrm{nM}$ [3]. At higher doses, this may play a role in its analgesic and antidepressant properties. Hyper-phenylalaninemia (HPA) serves as the most common inherited disorder of amino acid metabolism [4].

Amino acids are usually analyzed by liquid chromatographic methods [5], FTIR studies [6], differential capacitance, radioactive indicators, solid-phase extraction, flow injection [7, 8] electrochemiluminescence [9]. These methods are quite accurate, but they are dependent on multi-step sample clean-up procedures and are therefore relatively expensive and time consuming. For this reason, there is an interest in developing faster, simpler and lowcost procedures for amino acid analysis. In recent years, electrochemical detection has gained prominence as a sensitive and selective detection technique for the electroactive compounds. Various electroanalytical methods and sensors for the detection of amino acids have been reported [10-14]. 
In continuation of our earlier studies [15-19], we have now reported the fabrication of a new L-serine and L-phenylalanine biosensor based on carbon nanospheres $(\mathrm{CN})$, which was obtained by pyrolysis of bamboo. Electrochemical studies have been carried out using cyclic voltammetry (CV), differential pulse voltammetry (DPV), square wave voltammetry (SWV) and linear sweep voltammetry (LSV) for the detection of L-serine and L-phenylalanine in phosphate buffer solution (PBS) at $\mathrm{pH} 6.8$ and 7 , respectively. The studies revealed that the nanospheremodified electrode showed excellent sensitivity, selectivity, high stability, low potential along with a fast response towards the detection of these amino acids.

\section{Experimental section}

\section{Reagents and apparatus}

L-Serine, L-phenylalanine, sodium dihydrogen phosphate $\left(\mathrm{NaH}_{2} \mathrm{PO}_{4}\right)$ and disodium hydrogen phosphate $\left(\mathrm{Na}_{2} \mathrm{HPO}_{4}\right)$ and phosphoric acid $\left(\mathrm{H}_{3} \mathrm{PO}_{4}\right)$ were purchased from Sigma Aldrich. Pharmaceutical samples (Medett Products, India) of L-serine and L-phenylalanine were used for real sample analysis. All solutions were prepared with deionized water. Bamboo was carbonized in muffle furnace (Tanco, PL Tandon \& Company). The structure and morphology of $\mathrm{CN}$ were characterized by scanning electron microscope (SEM) (Hitachi X650, Japan), transmission electron microscope (TEM) (JEOL JEM 1400) and atomic force microscopy (AFM) (afm + Anasys). X-ray diffraction (XRD) patterns were recorded with JSO ISO DEBYEFLEX 2002 model X-ray powder diffractometer. Electrochemical studies were performed using a mini potentiostat (Dropsens $\mu$ stat 100). Pocket-sized pH meter (HANNA instrument) was used to maintain the $\mathrm{pH}$ of the sample solution.

$250 \mathrm{ml} 0.1 \mathrm{M}$ PBS ( $\mathrm{pH} \mathrm{7)}$ was prepared by mixing $0.22 \mathrm{~g}$ of $\mathrm{Na}_{2} \mathrm{HPO}_{4}$ and $0.3 \mathrm{~g}$ of $\mathrm{NaH}_{2} \mathrm{PO}_{4}$ in $250 \mathrm{ml}$ deionized water and adjusted the $\mathrm{pH}$ by the addition of $\mathrm{H}_{3} \mathrm{PO}_{4}$. The stock solution of $100 \mathrm{ml} 10^{-3} \mathrm{M}$ L-serine was prepared by dissolving $0.010 \mathrm{~g} \mathrm{~L}$-serine in $100 \mathrm{ml}$ of PBS (pH 6.8) and $100 \mathrm{ml} 10^{-3} \mathrm{ML}_{\mathrm{L}-\text { phenylalanine was prepared }}$ by dissolving $0.016 \mathrm{~g}$ of L-phenylalanine in $100 \mathrm{ml}$ of PBS ( $\mathrm{pH} 7)$. Standard solutions were prepared by diluting the stock solution in PBS by maintaining the $\mathrm{pH}$. Deionized water was used throughout this study.

Preparation, functionalization and characterization of carbon nanospheres from bamboo $(\mathrm{CN})$

$\mathrm{CN}$ was prepared by our own reported method [16] by carbonizing the pieces of bamboo at $600-650{ }^{\circ} \mathrm{C}$ under insufficient flow of air in a muffle furnace. For purification, carbon soot was collected in a thimble and then placed in a soxhlet extractor for sequential purification with petroleum ether, acetone, ethyl alcohol and finally with water. Unburnt bamboo and other unwanted form of carbon can be removed by this method. For functionalization, $250 \mathrm{ml}$ $2 \mathrm{M} \mathrm{HNO}_{3}$ was mixed with the carbon soot and stirred for several minutes and then kept undisturbed overnight. To remove excess nitrate, it was then repeatedly dissolved in water and then evaporated to dryness. Complete removal of nitrate was confirmed by Griess's test [20]. For further purification, it was re-precipitated with alcohol and water. It was then characterized by SEM, TEM, AFM, XRD.

Fabrication of $\mathrm{CN}$ electrode

As reported earlier [19], the $\mathrm{CN}$ electrode was designed like the commercially available standard electrode DS110CNT. It was fabricated on Teflon material containing three silver wires, where both working and counter electrodes were made of $\mathrm{CN}$ and third silver wire was acted as reference electrode. For the fabrication of the electrode, polystyrene solution was first prepared in chloroform (9:1 ratio). Then, $\mathrm{CN}$ was mixed with polystyrene solution using mechanical stirrer followed by sonication. A drop of the slurry was then deposited as a very fine thin film on the two silver wires, serving as working and counter electrodes. The electrode has a dimension of $3.5 \times 1.0 \times 0.5 \mathrm{~cm}$ (length $\times$ width $\times$ height $)$ and it was ideal for working with $50 \mu$ volume like the standard electrode.

L-Serine and L-phenylalanine detection with fabricated $\mathrm{CN}$ electrode

For the detection of L-serine, electrochemical studies such as CV, DPV, and LSV studies were performed with the sample solutions in phosphate buffer solution at $\mathrm{CN}$ electrode and CV, SWV and LSV studies were performed for L-phenylalanine detection. $\mathrm{pH} 6.8$ was maintained for L-serine detection and $\mathrm{pH} 7$ was maintained for L-phenylalanine detection. To optimize the conditions of electrochemical detection of both the amino acids at $\mathrm{CN}$ electrode, effect of $\mathrm{pH}$, scan rate, time interval were studied in detail. Then, the linearity, detection limit, sensitivity, reproducibility and stability of the sensor were also investigated. To determine the selectivity of the sensor, the effect of the presence of some small biomolecules on the current responses of $\mathrm{L}$-serine and $\mathrm{L}$-phenylalanine at $\mathrm{CN}$ electrode was evaluated under optimized experimental conditions. The utility of the $\mathrm{CN}$ electrode was tested by determining the amino acids in some pharmaceutical samples. 
Fig. 1 a SEM image of carbon nanospheres $(\mathrm{CN})$, b TEM image of carbon nanospheres $(\mathrm{CN})$
Fig. 2 a AFM image of carbon nanospheres $(\mathrm{CN}), \mathbf{b}$ XRD pattern of carbon nanospheres $(\mathrm{CN})$
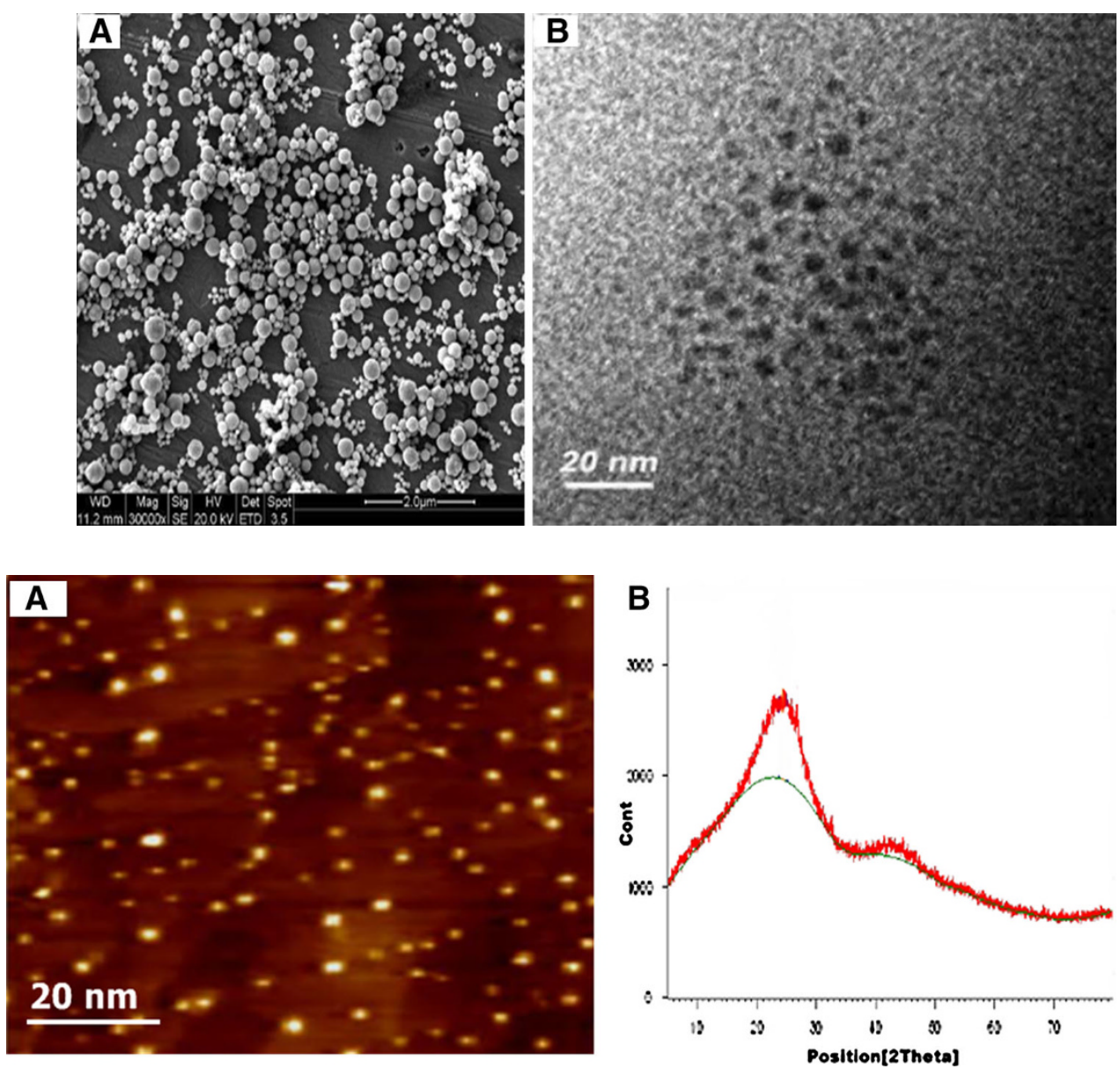

\section{Results and discussion}

\section{Characterizations of $\mathrm{CN}$}

As reported earlier [16], surface morphological studies were done by SEM, TEM studies. Figure 1a shows the SEM image of carbon nanospheres in the range of $300-600 \mathrm{~nm}$. Figure $1 \mathrm{~b}$ shows the TEM image of uniformly distributed carbon nanospheres and it clearly indicates the formation of carbon nano particles of spherical like structures. AFM image in Fig. 2a further confirms the formation of carbon nanospheres. XRD pattern of $\mathrm{CN}$ (Fig. 2b) shows two intensed peak at $25^{\circ}$ and $44^{\circ}$ which were assigned for (002) and (001) reflections, respectively, and confirms $\mathrm{CN}$ formation.

Effect of $\mathrm{pH}$ on the peak current of L-serine and L-phenylalanine at $\mathrm{CN}$ electrode

Effect of solution $\mathrm{pH}$ on the oxidation of $10^{-5} \mathrm{M}$ L-serine and L-phenylalanine at $\mathrm{CN}$-modified electrode was investigated by LSV in the $\mathrm{pH}$ range from 6.5 to 8.5 by mixing $\mathrm{Na}_{2} \mathrm{HPO}_{4}, \mathrm{NaH}_{2} \mathrm{PO}_{4}$ and $\mathrm{H}_{3} \mathrm{PO}_{4}$. Figure $3 \mathrm{a}$, b show that there is a gradual decrease of the oxidation peak current with the increasing $\mathrm{pH}$ for both amino acids, beyond the value of 6.8 for $\mathrm{L}$-serine and 7 for $\mathrm{L}$-phenylalanine. $I / \mu \mathrm{A}$ vs. $\mathrm{pH}$ graph shows that for L-serine, maximum peak current is observed at $\mathrm{pH} 6.8$ and for $\mathrm{L}-\mathrm{phenylalanine}$ at $\mathrm{pH} 7$. Therefore, the $\mathrm{pH}$ 6.8 and 7 were chosen for the subsequent analytical experiments for L-serine and L-phenylalanine, respectively.

CV studies to determine the effect of scan rate on the peak current and peak potential of L-serine and L-phenylalanine at $\mathrm{CN}$ electrode

In both cases, $\mathrm{CV}$ studies were performed with $10^{-5} \mathrm{M}$ L-serine $(\mathrm{pH} 6.8)$ and L-phenylalanine $(\mathrm{pH} 7)$ solutions in PBS at $100 \mathrm{mV} \mathrm{s}^{-1}$ on bare silver electrode (Blank) (Fig. 4). No peak current was observed at the potential range $0.05-0.09 \mathrm{~V}$, which indicates that on bare silver electrode no reactions took place.

The effect of the scan rate on the electrochemical detection of L-serine and L-phenylalanine at the $\mathrm{CN}$ electrode was investigated by voltammetric techniques. Figure $5 \mathrm{a}, \mathrm{b}$ displays the overlaps of cyclic voltagrams of $10^{-5} \mathrm{M}$ L-serine ( $\mathrm{pH}$ 6.8) and L-phenylalanine ( $\left.\mathrm{pH} 7.0\right)$, respectively, at various scan rates in PBS, while the inset shows the $3 \mathrm{D}$ representation of CVs. The current $(I / \mu \mathrm{A})$ vs. 
Fig. 3 a Effect of solution $\mathrm{pH}$ on the oxidation peak current of $10^{-5} \mathrm{M}$ L-serine in PBS ( $\mathrm{pH}$ $6.8)$ at $100 \mathrm{mV} \mathrm{s}^{-1}$. b Effect of solution $\mathrm{pH}$ on the oxidation peak current of $10^{-5} \mathrm{M}$ L-phenylalanine in PBS (pH 7) at $100 \mathrm{mV} \mathrm{s}^{-1}$
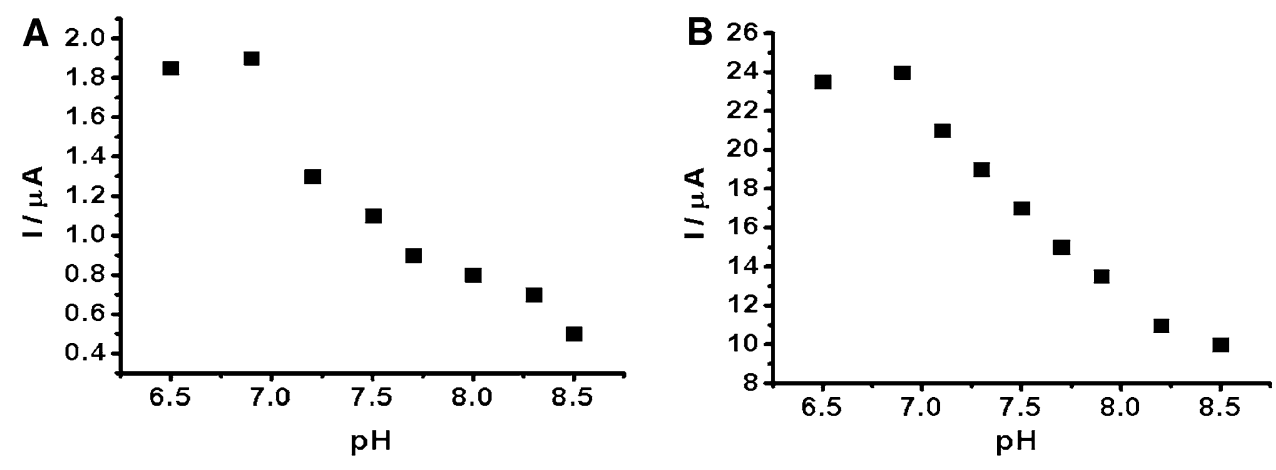

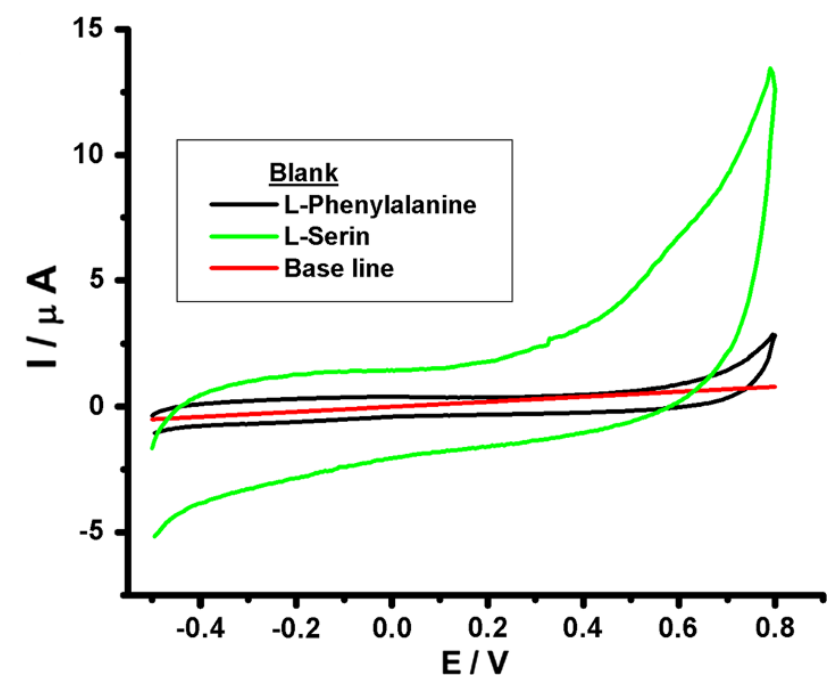

Fig. 4 CVs of $10^{-5} \mathrm{M}$ L-serine and L-phenylalanine at silver electrode in PBS at $100 \mathrm{mV} \mathrm{s}^{-1}$ scan rate (blank)

scan rate $\left(v / \mathrm{mV} \mathrm{s}^{-1}\right)$ plot, shown in the inset, exhibits a linear relationship with $R^{2}=0.99589$ for $\mathrm{L}$-serine and $R^{2}=0.99719$ for L-phenylalanine.

The influence of scan rate was investigated within the range of $50-140 \mathrm{mV} \mathrm{s}^{-1}$ for L-serine and $50-150 \mathrm{mV} \mathrm{s}^{-1}$ for L-phenylalanine. The linearity was observed over the entire range of scan rates studied and it indicates that the electrochemical kinetics reaction is adsorption controlled [21]. Potential required for the detection of L-serine on $\mathrm{CN}$ electrode was found to be $0.085 \mathrm{~V}$ and for L-phenylalanine is $0.06 \mathrm{~V}$.

DPV, LSV and SWV studies to determine the effect of time interval on the peak current and peak potential of L-serine and L-phenylalanine at $\mathrm{CN}$ electrode

Beside CV studies, other electrochemical studies were also performed to check the nature of peak current and peak potential and also to check the maximum accumulation time for both the amino acids. Interestingly, it was observed that sharp intense peaks were obtained without changing the peak potential.
Figure $6 \mathrm{a}, \mathrm{b}$ shows the DPV and LSV 2D and 3D plots of $10^{-5} \mathrm{M}$ L-serine at various time intervals $(2-10 \mathrm{~min})$ and at $22 \mathrm{mV} \mathrm{s}^{-1}$ for DPV ( $t$ pulse $=0.07 \mathrm{~s}$ ), $100 \mathrm{mV} \mathrm{s}^{-1}$ for LSV scan rate in PBS, maintaining the $\mathrm{pH}$ at 6.8. A good linear relationship between current and the entire range of time interval studied was observed in each case.

$$
\begin{aligned}
I / \mu \mathrm{A} & =4.22+0.23 \min , R^{2}=0.99438, \\
\mathrm{SD} & =0.089, N=5(\mathrm{DPV}) \\
I / \mu \mathrm{A} & =1.28+0.055 \mathrm{~min}, R^{2}=0.99589 \\
\mathrm{SD} & =0.018, N=5(\mathrm{LSV})
\end{aligned}
$$

Figure 7a, b shows the SWV and LSV 2D and 3D plots of $10^{-5} \mathrm{M}$ L-phenylalanine in $\mathrm{PBS}$ ( $\mathrm{pH} 7$ ) with various time intervals. For SWV studies, the frequency was adjusted to $12 \mathrm{~Hz}$ and $E_{\mathrm{ampl}}=0.010 \mathrm{~V}$ and $\mathrm{LSV}$ was performed at a scan rate of $100 \mathrm{mV} \mathrm{s}^{-1}$. For both $\mathrm{SWV}$ and LSV, the studies were conducted up to $20 \mathrm{~min}$ and here also, a good linear relationship between current and the time interval was observed in each case.

$$
\begin{aligned}
I / \mu \mathrm{A} & =20.656+0.536 \mathrm{~min}, R^{2}=0.99719 \\
\mathrm{SD} & =0.278, N=8(\mathrm{SWV}) \\
I / \mu \mathrm{A} & =20.426+0.183 \mathrm{~min}, R^{2}=0.99822 \\
\mathrm{SD} & =0.070, N=10(\mathrm{LSV})
\end{aligned}
$$

In each and every case, the peak current increases linearly with time up to a certain period of time, but when these studies were conducted over a more extended time interval range then there was a breakdown in the linearity relationship which may be due to the stabilization of current with time. Therefore, for $10^{-5} \mathrm{M}$ L-serine and L-phenylalanine, the maximum accumulation times, 10 and 20 min, respectively, were employed.

Linearity, detection limit, stability and sensitivity of the L-serine and L-phenylalanine sensor

Figure 8a shows the $\mathrm{CV}$ of different concentrations of L-serine at $\mathrm{pH} 6.8$ and Fig. $8 \mathrm{~b}$ shows the LSV of different concentrations of L-phenylalanine in PBS at pH 7. As LSV studies gave more intensed peak than $\mathrm{CV}$ in case of 
A

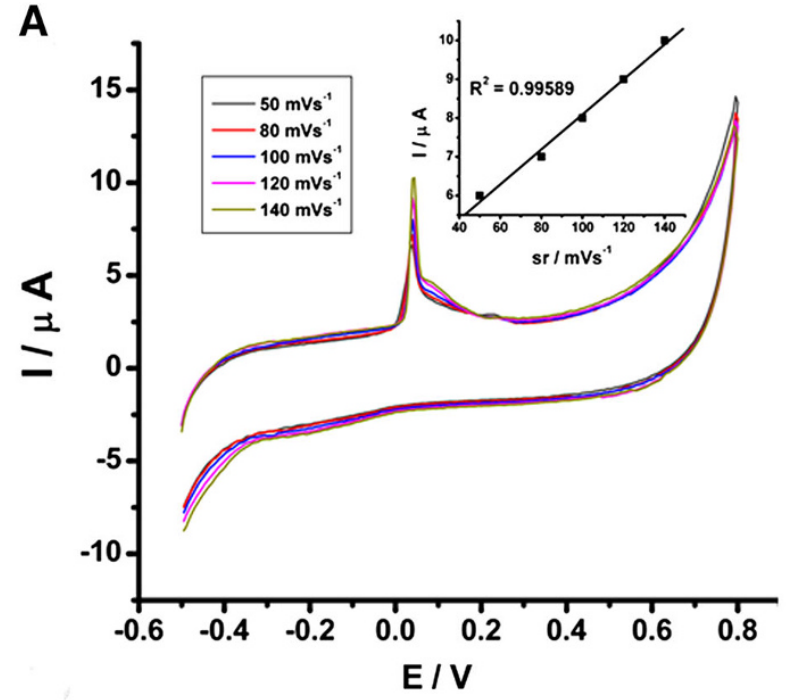

B

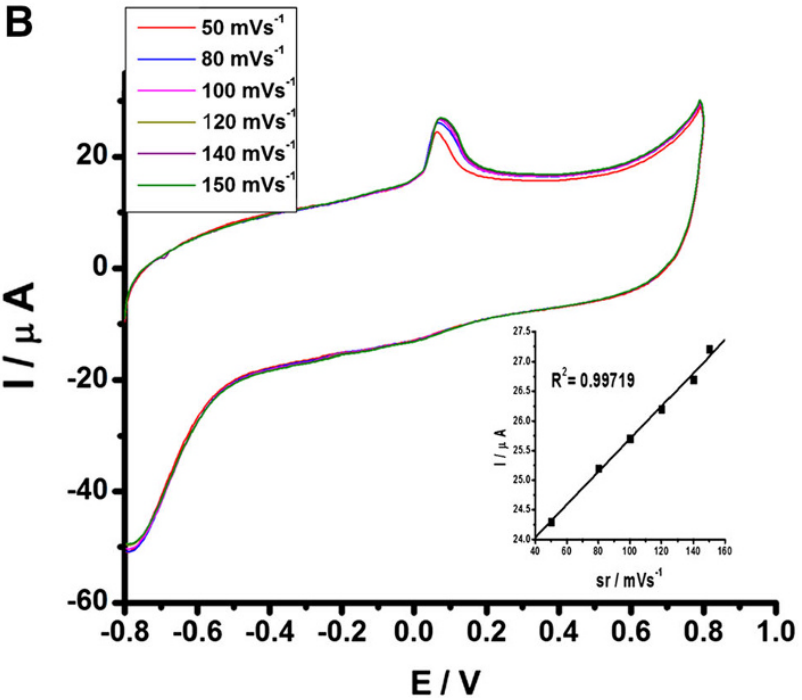

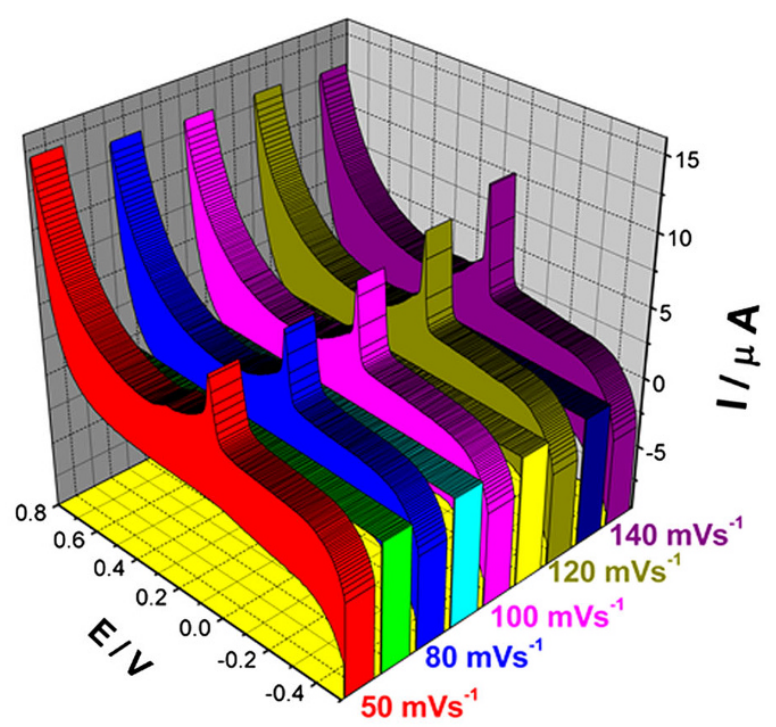

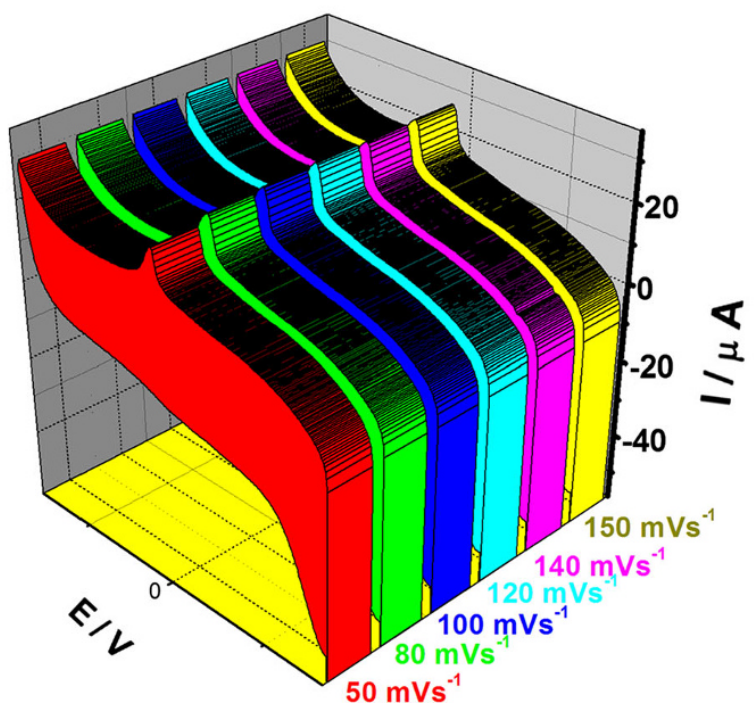

L-phenylalanine in PBS (pH 7) at various scan rates $(50,80,100$, 120,140 and $150 \mathrm{mV} \mathrm{s}^{-1}$ ) on $\mathrm{CN}$-modified electrode. Inset the plot of peak current $(I / \mu \mathrm{A})$ versus scan rate $\left(\nu / \mathrm{mV} \mathrm{s}^{-1}\right)$

$0.1 \mathrm{M} \mathrm{H}_{2} \mathrm{SO}_{4}$ as a redox probe at various scan rate and using Randles-Sevcik equation, $I_{\mathrm{P}}=\left(2.69 \times 10^{5}\right)$ $n^{3 / 2} A D^{1 / 2} C v^{1 / 2}$, where $n$ is the number of electrons participating in the redox reaction, $A$ is the electroactive surface area $\left(\mathrm{cm}^{2}\right), D$ is the diffusion coefficient $\left(\mathrm{cm}^{2} \mathrm{~s}^{-1}\right), C$ is the concentration of the redox probe molecule $\left(\mathrm{mol} \mathrm{cm}^{-3}\right)$ and $v$ is the scan rate $\left(\mathrm{mV} \mathrm{s}^{-1}\right)$. The calculated electroactive surface area of $\mathrm{CN}$ electrode was found to be $0.125 \mathrm{~cm}^{2}$, where $C=5 \times 10^{-4} \mathrm{M}, D=7.1 \times 10^{-6} \mathrm{~cm}^{2} \mathrm{~s}^{-1}, n=1$ for $\left[\mathrm{Fe}(\mathrm{CN})_{6}\right]^{3-/ 4-}$ system.

The sensitivity was calculated using the slope of the current versus concentration calibration plot (Fig. 8a, b inset) divided by the active surface area of $\mathrm{CN}$ according to the following equation [22]:

with the help of $\mathrm{CV}$ studies of $5 \times 10^{-4} \mathrm{M} \mathrm{K}_{4}\left[\mathrm{Fe}(\mathrm{CN})_{6}\right]$ in 

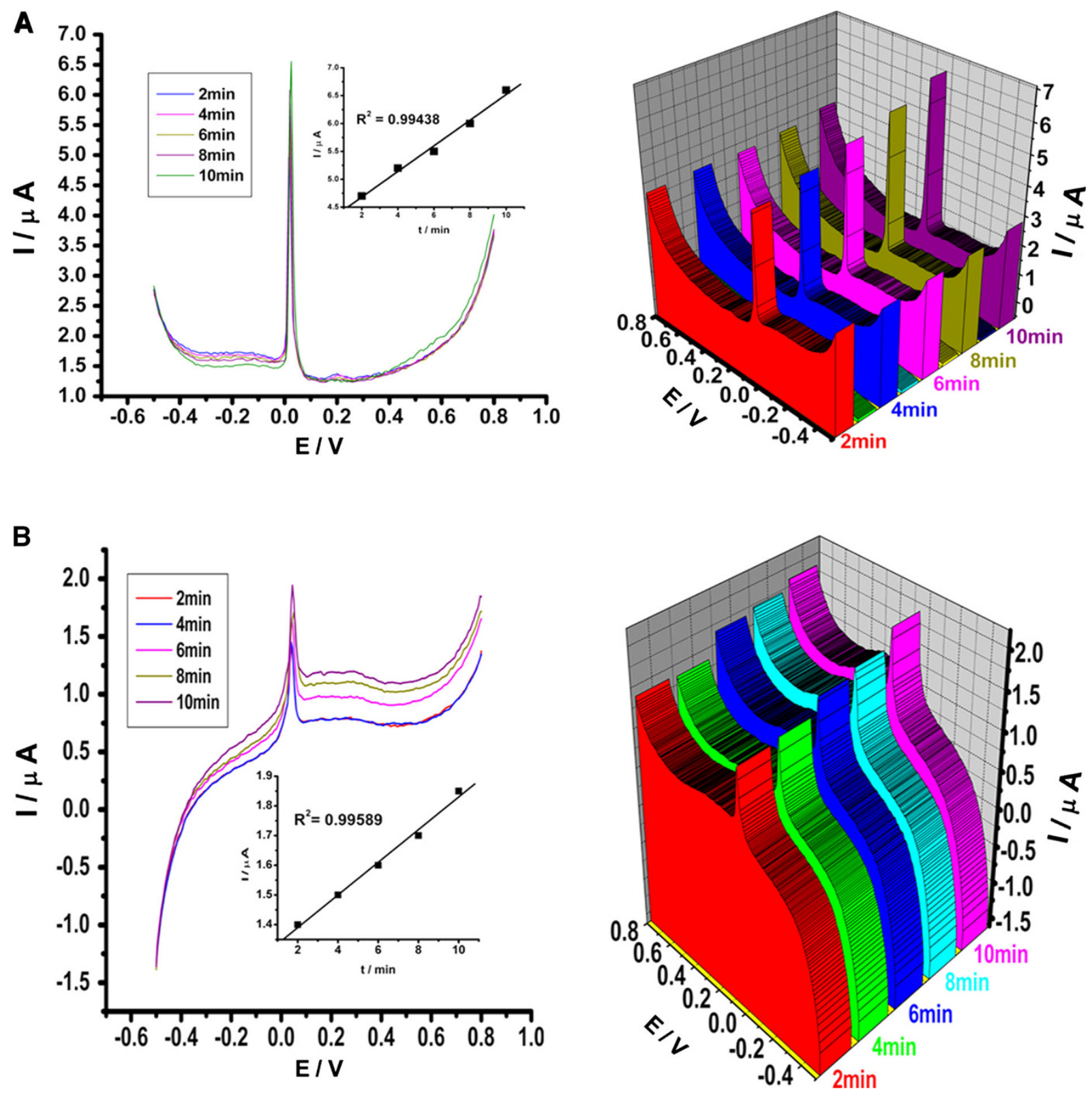

Fig. 6 a $2 \mathrm{D}$ and $3 \mathrm{D}$ plots of DPVs of $10^{-5} \mathrm{M}$ L-serine at $\mathrm{CN}$ electrode in PBS (pH 6.8) in various time interval (2, 4, 6, 8 and $10 \mathrm{~min})$ at $22 \mathrm{mV} \mathrm{s}^{-1}$ scan rate $(t$ pulse $=0.07 \mathrm{~s})$. Inset the plot of peak current $(I / \mu \mathrm{A})$ versus time interval $(t / \mathrm{min})$. b $2 \mathrm{D}$ and $3 \mathrm{D}$ plots of

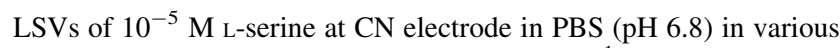
time interval $(2,4,6,8$ and $10 \mathrm{~min})$ at $100 \mathrm{mV} \mathrm{s}^{-1}$ scan rate. Inset the plot of peak current $(I / \mu \mathrm{A})$ versus time interval $(t / \mathrm{min})$

\section{Sensitivity}

$=$ slope of the plot/active surface area of the electrode

The sensitivity of the $\mathrm{CN}_{\mathrm{L}}$-serine sensor was calculated to be $\sim 5.21 \mu \mathrm{A} \mu \mathrm{M}^{-1} \mathrm{~cm}^{-2}$ (slope $=0.664 \mu \mathrm{A} \mu \mathrm{M}^{-1}$ )

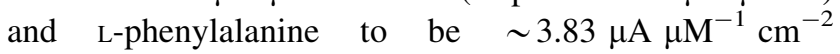

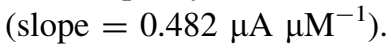

The limit of detection (LOD) for both amino acids was calculated using the following equation: $\mathrm{LOD}=3 \mathrm{~s} / \mathrm{m}$;

where $s$ is the standard deviation of the peak currents of the blank (five runs), and $m$ is the slope of the calibration curve [23], and the values were found to be $0.54 \mu \mathrm{M}$ for L-serine and $1 \mu \mathrm{M}$ for L-phenylalanine.

Series of five successive LSV measurements with $10^{-5} \mathrm{M}$ L-serine $(\mathrm{pH}=6.8)$ and L-phenylalanine in PBS $(\mathrm{pH}=7)$, each recorded on a new modified $\mathrm{CN}$ electrode, yielded relative standard deviations of 2.8 and $2.5 \%$, respectively (Fig. 9). The results indicate that $\mathrm{CN}$ electrode provides good reproducibility towards oxidation of both 

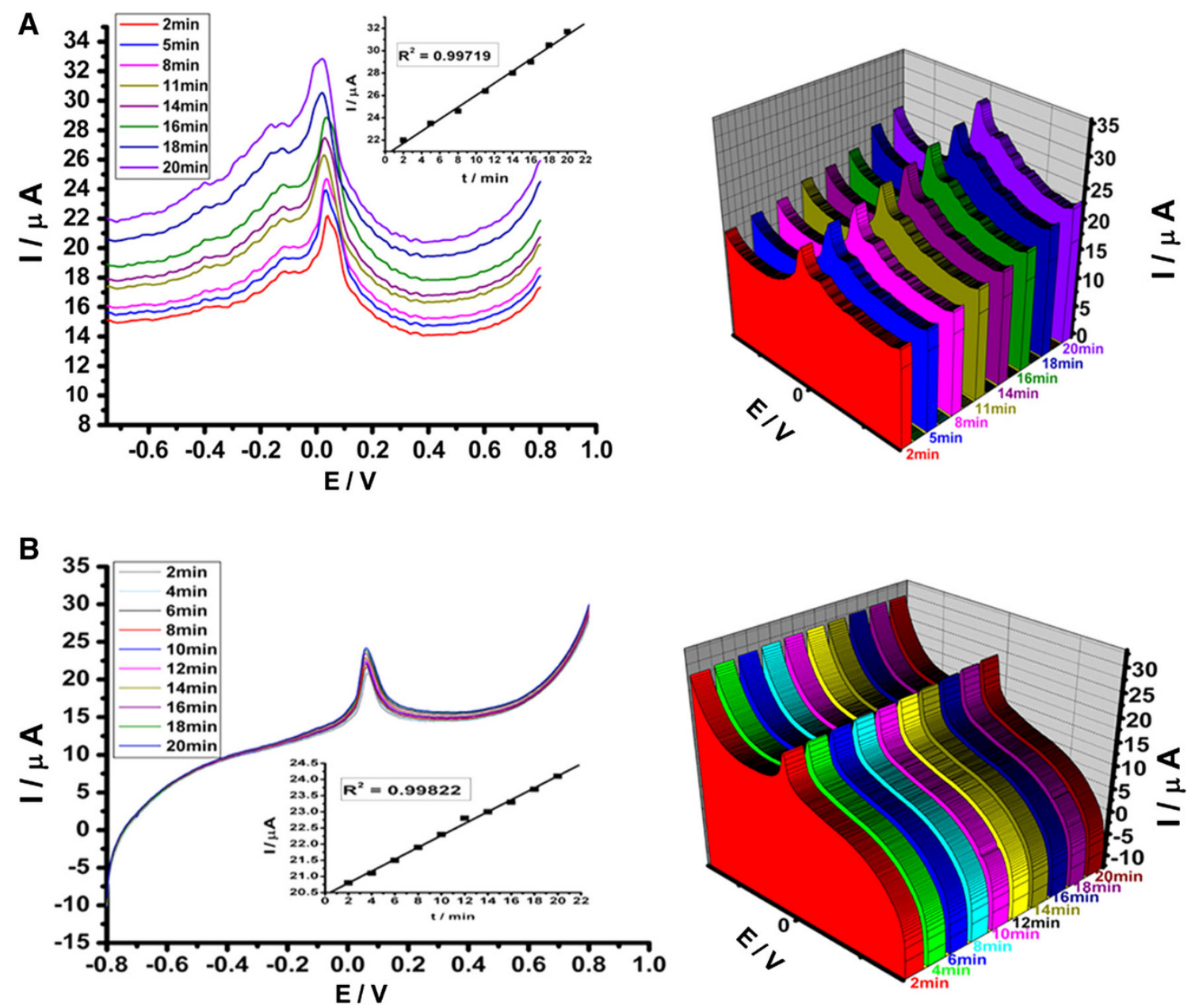

Fig. 7 a $2 \mathrm{D}$ and $3 \mathrm{D}$ plots of SWVs of $10^{-5} \mathrm{M}_{\mathrm{L}-\text { phenylalanine at } \mathrm{CN}}$ electrode in PBS ( $\mathrm{pH} 7)$ in various time interval $(2,5,8,11,14,16,18$ and $20 \mathrm{~min}$ ) at $100 \mathrm{mV} \mathrm{s}^{-1}$ scan rate. Inset the plot of peak current $(I / \mu \mathrm{A})$ versus time interval $(t / \mathrm{min})$. b $2 \mathrm{D}$ and $3 \mathrm{D}$ plots of LSVs of
$10^{-5} \mathrm{M}$ L-phenylalanine at $\mathrm{CN}$ electrode in PBS (pH 7) in various time interval $(2,4,6,8,10,12,14,16,18$ and $20 \mathrm{~min})$ at $100 \mathrm{mV} \mathrm{s}^{-1}$ scan rate. Inset the plot of peak current $(I / \mu \mathrm{A})$ versus time interval $(t / \min )$
Fig. 8 a $\mathrm{CV}$ s at $\mathrm{CN}$ electrode in PBS (pH 6.8) with different concentrations of L-serine $(1-100 \mu \mathrm{M})$ at $100 \mathrm{mV} \mathrm{s}^{-1}$ scan rate. Inset calibration curve of response current $(I / \mu \mathrm{A})$ versus $\mathrm{L}$-serine concentration (Conc./ $\mu \mathrm{M})$. b LSVs at $\mathrm{CN}$ electrode in PBS (pH 7) with different concentrations of L-phenylalanine $(1-100 \mu \mathrm{M})$ at $100 \mathrm{mV} \mathrm{s}^{-1}$ scan rate. Inset calibration curve of response current $(I / \mu \mathrm{A})$ versus L-phenylalanine concentration (Conc. $/ \mu \mathrm{M})$

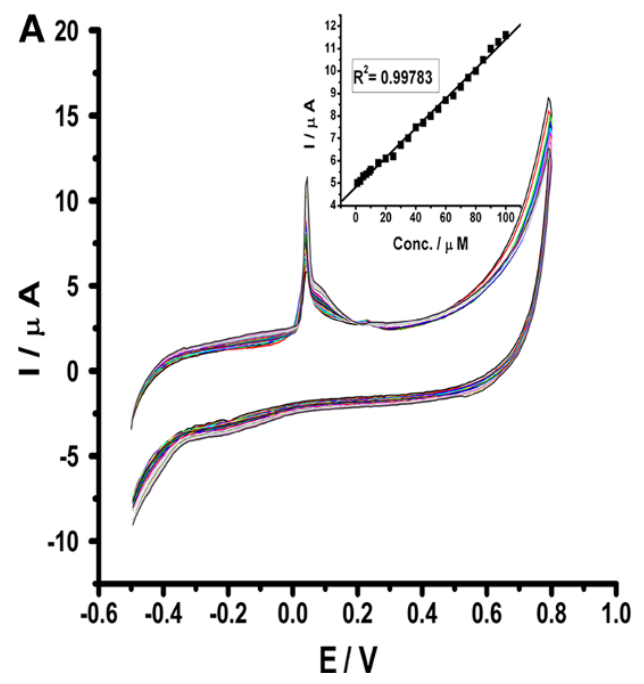

B

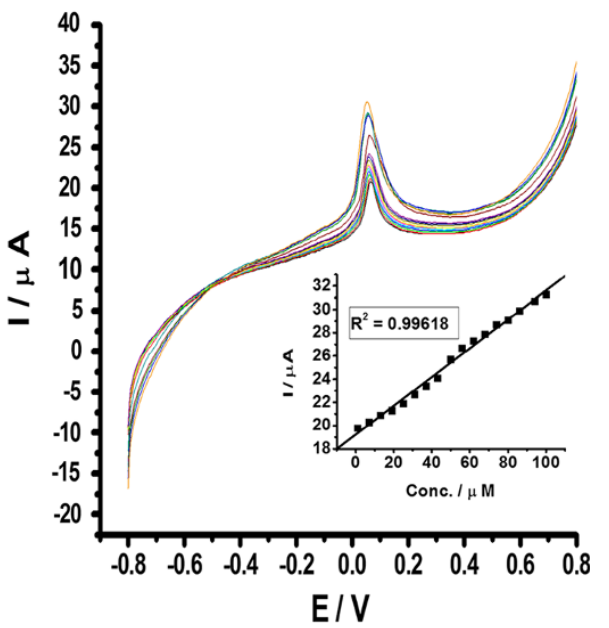



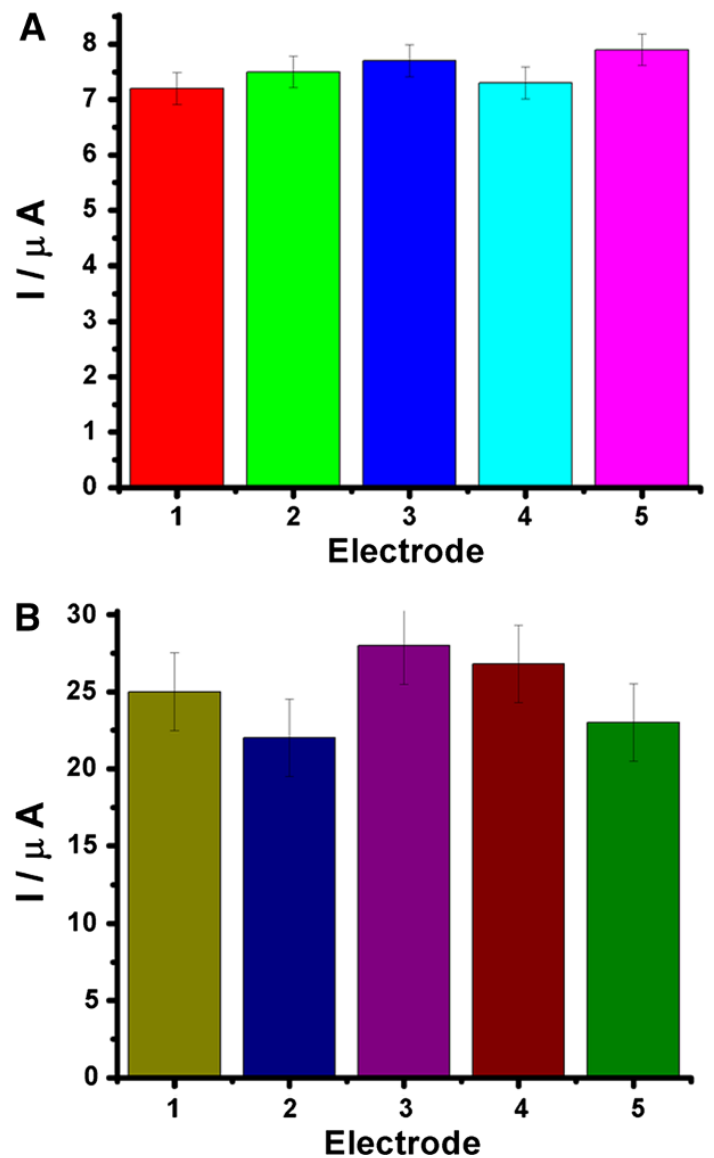

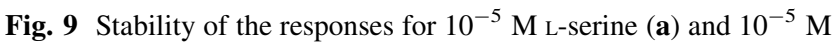
L-phenylalanine (b), obtained at five different modified $\mathrm{CN}$ electrode. For L-serine $N=5, \mathrm{RSD}=2.8 \%$ and for L-phenylalanine $N=5$, $\mathrm{RSD}=2.5 \%$

amino acids. The stability of the amino acid sensor was also explored when the modified electrode was stored in air for 15 days, where the current response of $10^{-5} \mathrm{M}_{\mathrm{L}}$-serine and L-phenylalanine was found to be stable maintaining $\sim 90 \%$ of its initial intensity.

\section{Interference}

During the electrochemical studies of a sensor, it is necessary to conduct the experiments at a particular potential, which can only drive the reaction of interest. Under optimized experimental conditions described above, the effects of some small biomolecules on the current responses of $10^{-5} \mathrm{M} \mathrm{L}$-serine and L-phenylalanine have been evaluated. Uric acid, vitamin $\mathrm{C}$, dopamine, L-alanine, glycine, tryptophan, and tyrosine have no influence on the current response at $\mathrm{CN}$ electrode in PBS at $\mathrm{pH} 6.8$ and 7. The experimental results (Tables 1,2) showed that ten times of each substance had almost no interference with the determination of L-serine and L-phenylalanine. So, it can be
Table 1 Influence of interfering species on the voltammetric response of $10^{-5} \mathrm{M} \mathrm{L}$-serine at $\mathrm{CN}$ electrode

\begin{tabular}{llll}
\hline $\begin{array}{l}\text { L-Serine }\left(10^{-5} \mathrm{M}\right)+\text { interfering } \\
\text { species }\left(10^{-4} \mathrm{M}\right)\end{array}$ & $\begin{array}{l}\text { Observed } \\
\text { potential } \\
(\mathrm{V})\end{array}$ & $\begin{array}{l}\text { Signal } \\
\text { change } \\
(\%)\end{array}$ & $\begin{array}{l}\text { Average } \\
\text { signal } \\
\text { change }(\%)\end{array}$ \\
\hline L-Serine & 0.0852 & 0 & \\
L-Serine + uric acid & 0.0855 & 0.352 & \\
L-Serine + vitamin-C & 0.086 & 0.939 & \\
L-Serine + dopamine & 0.0859 & 0.939 & 0.7051 \\
L-Serine + L-alanine & 0.0847 & 0.587 & \\
L-Serine + glycine & 0.0852 & 0 & \\
L-Serine + tryptophan & 0.0845 & 0.828 & \\
L-Serine + tyrosine & 0.0863 & 1.291 & \\
\hline
\end{tabular}

Table 2 Influence of interfering species on the voltammetric response of $10^{-5} \mathrm{M}$ L-phenylalanine at $\mathrm{CN}$ electrode

\begin{tabular}{llll}
\hline $\begin{array}{l}\text { L-Serine }\left(10^{-5} \mathrm{M}\right)+\text { interfering } \\
\text { species }\left(10^{-4} \mathrm{M}\right)\end{array}$ & $\begin{array}{l}\text { Observed } \\
\text { potential } \\
(\mathrm{V})\end{array}$ & $\begin{array}{l}\text { Signal } \\
\text { change } \\
(\%)\end{array}$ & $\begin{array}{l}\text { Average } \\
\text { signal } \\
\text { change }(\%)\end{array}$ \\
\hline L-Phenylalanine & 0.0613 & 0 & \\
L-Phenylalanine + uric acid & 0.0617 & 0.652 & \\
L-Phenylalanine + Vitamin-C & 0.0611 & 0.326 & \\
L-Phenylalanine + dopamine & 0.0621 & 1.305 & 0.675 \\
L-Phenylalanine + L-alanine & 0.0616 & 0.489 & \\
L-Phenylalanine + glycine & 0.0615 & 0.326 & \\
L-Phenylalanine + tryptophan & 0.0609 & 0.652 & \\
L-Phenylalanine + tyrosine & 0.0607 & 0.978 & \\
\hline
\end{tabular}

concluded that the proposed method is able to assay both the amino acids in the presence of interfering substances and hence it can be considered specific. The average signal change was found to be $0.7051 \%$ for L-serine and $0.675 \%$ for L-phenylalanine.

Determination of amino acids in pharmaceutical samples

L-Serine and L-phenylalanine were determined in some pharmaceutical samples (Medett Products, India) using the proposed method. Preparation of sample solution was as same as mentioned in the "Reagents and apparatus" $10^{-5} \mathrm{M}$ sample solution was prepared in PBS at desired $\mathrm{pH}$ and LSV studies were performed. Table 3 summarizes the results obtained from voltammetric determination of L-serine and L-phenylalanine along with the certified values of the analyzed pharmaceutical products.

The above results suggest that $\mathrm{CN}$ electrode is very reliable and sensitive enough for the determination of these amino acids ion real samples. 
Table 3 Results obtained for the determination of L-serine and L-phenylalanine in pharmaceutical products using modified $\mathrm{CN}$ electrode

\begin{tabular}{lllll}
\hline Sample & $\begin{array}{l}\text { CN-modified } \\
\text { sensor }(\mathrm{g})\end{array}$ & $\begin{array}{l}\text { Certified } \\
\text { value }(\mathrm{g})\end{array}$ & $\begin{array}{l}\text { Recovery } \\
(\%)\end{array}$ & $\begin{array}{l}\text { Bias } \\
(\%)\end{array}$ \\
\hline L-Serine & $1.47 \pm 0.02^{\mathrm{a}}$ & 1.5 & 98 & 2 \\
L-Phenylalanine & $1.46 \pm 0.01^{\mathrm{a}}$ & 1.5 & 97.3 & 2.6 \\
\hline
\end{tabular}

${ }^{\text {a }}$ Average of five determinations

\section{Conclusions}

In this study, a carbon nanosphere-modified electrode was prepared and it was applied for the detection of L-serine and L-phenylalanine using CV, DPV, SWV and LSV. The prepared electrode was found to have excellent electrocatalytic activity towards both the amino acids' detection. In both the cases, the oxidation peak current was linearly proportional to its concentration over the range from $10^{-4}$ to $10^{-6} \mathrm{M}(1-100 \mu \mathrm{M})$ with a very low detection limit (correlation coefficient of 0.99783 for L-serine and 0.99618 for L-phenylalanine). This modified sensor showed excellent sensitivity, selectivity and strong stability. This paper also demonstrates the suitability of $\mathrm{CN}$ electrode for fast analysis of L-serine and L-phenylalanine in standard solutions as well as in commercial pharmaceutical products.

Acknowledgments The authors are grateful to the Director, NIT Agartala to allow for publishing the results. IIT, Kanpur is greatly acknowledged for characterization like SEM, TEM, AFM, etc. Authors are also thankful to AICTE, New Delhi for financial support.

Conflict of interest The authors declare that they have no competing interests.

Author contributions SD has been involved in experimental works. SD has also made substantial contributions to the analysis and interpretation of data. SD and MS carried out the manuscript preparation. MS has given final approval of the version to be published.

Open Access This article is distributed under the terms of the Creative Commons Attribution License which permits any use, distribution, and reproduction in any medium, provided the original author(s) and the source are credited.

\section{References}

1. Elsila, J.E., Dworkin, J.P., Bernstein, M.P., Martin, M.P., Sandford, S.A.: Mechanisms of amino acid formation in interstellar ice analogs. Astrophys. J. 660, 911-918 (2007)

2. deKoning, T.J., Snell, K., Duran, M., Berger, R., Poll-The, B.T., Surtees, R.: L-serine in disease and development. Biochem. J. 371, 653-661 (2003)

3. Mortell, K.H., Anderson, D.J., Lynch, J.J., Sherry, L.N., Kathy Sarris, McDonald, H., Reza, S., Scott, B., Prisca, H., Lee, C.H., Michael, F.J., Murali, G.: Structure-activity relationships of $\alpha$-amino acid ligands for the $\alpha 2 \delta$ subunit of voltage-gated calcium channels. Bioorg. Med. Chem. Lett. 16(5), 1138-1141 (2006)

4. Nelson, D.L., Cox, M.M.: Lehninger, Principles of Biochemistry, 3rd edn. Worth Publishing, New York (2000). ISBN 1-57259$153-6$

5. Heftmann, E.: Chromatography, Fundamentals and Applications of Chromatography and Related Differential Migration Methods Part B: Applications, 5th edn. Elsevier, Amsterdam (1992)

6. Li, H.Q., Chen, A., Roscoe, S.G., Lipkowski, J.: Electrochemical and FTIR studies of L-phenylalanine adsorption at the $\mathrm{Au}(111)$ electrode. J. Electroanal. Chem. 500, 299-310 (2001)

7. Grudpan, K., Kamfoo, K.: Flow injection dialysis for the determination of anions using ion chromatography. Talanta 49, 1023-1026 (1999)

8. Alwarthan, A.A.: Determination of ascorbic-acid by flow-injection with chemiluminescence detection. Analyst 118, 639-642 (1993)

9. Agater, I.B., Jewsbury, R.A.: Direct chemiluminescence determination of ascorbic acid using flow injection analysis. Anal. Chim. Acta 356, 289-294 (1997)

10. Keyvanfard, M., Shakeri, R., Maleh, H.K., Alizad, K.: Highly selective and sensitive voltammetric sensor based on modified multiwall carbon nanotube paste electrode for simultaneous determination of ascorbic acid, acetaminophen and tryptophan Mater. Sci. Eng. C 33, 811-816 (2013)

11. Daud, N., Yusof, N.A., Tee, T.W., Abdullah, A.H.: Electrochemical sensor for As(III) utilizing CNTs/leucine/nafion modified electrode. Int. J. Electrochem. Sci. 7, 175-185 (2012)

12. Akhtar, P., Too, C.O., Wallace, G.G.: Detection of amino acids at conducting electroactive polymer modified electrodes using flow injection analysis. Part II. Use of microelectrodes. Anal. Chim. Acta 339, 211-223 (1997)

13. Li, H., Li, T., Wang, E.: Electrocatalytic oxidation and flow detection of cysteine at an aquocobalamin adsorbed glassy carbon electrode. Talanta 42, 885-888 (1995)

14. Tony, T., Ronald, J.M., Praveen, M., Zineb, M., Swamy, B.E.K.: Multi-walled carbon nanotube modified carbon paste electrode as an electrochemical sensor for the determination of epinephrine in the presence of ascorbic acid and uric acid. Mater. Sci. Eng. C 33, 3294-3302 (2013)

15. Das, S., Saha, M.: Non enzymatic electrochemical detection of glucose at rice starch-nanoparticles modified electrode. Int. J. Pharm. Bio. Sci. 4, 967-975 (2013)

16. Das, S., Saha, M.: Preparation of carbon nanosphere from bamboo and its use in water purification. Curr. Trends Tech. Sci. 2, 174-177 (2013)

17. Das, S., Saha, M.: Electrochemical studies of carbon nanotube obtained from coconut oil as non enzymatic glucose biosensor. Adv. Sci. Eng. Med. 5, 645-648 (2013)

18. Sonkar, S.K., Saxena, M., Saha, M., Sarkar, S.: Carbon nanocubes and nanobricks from pyrolysis of rice. J. Nanosci. Nanotech. 10, 1-4 (2010)

19. Saha, M., Das, S.: Fabrication of a nonenzymatic cholesterol biosensor using carbon nanotubes from coconut oil. J. Nanostruct. Chem. 4, 94-102 (2014). doi:10.1007/s40097-014-0094-1

20. Heines, V.: Peter Griess discoverer of diazo compounds. J. Chem. Educ. 35, 187-191 (1958)

21. Swartz, E., Krull, I.S.: Analytical Method Development and Validation. Marcel Dekkar, New York (1997)

22. Tian, H., Jia, M., Zhang, M., Hu, J.: Nonenzymatic glucose sensor based on nickel ion implanted-modified indium tin oxide electrode. Electrochim. Acta 96, 285-290 (2013)

23. Dar, G.N., Umar, A., Zaidi, S.A., Ibrahim, A.A., Abaker, M., Baskoutas, S., Al-Assir, M.S.: Ce doped $\mathrm{ZnO}$ nanorods for the detection of hazardous chemical. Sens. Actuat. B Chem. 173, 72-75 (2012) 